\title{
Studies on the Therapeutic Efficacy of Certain Dyes in Leprosy.
}

G. R. RAO.

\section{INTRODUCTION.}

A T the suggestion of Dr. C. S. Ryles, of Dhanbad, in September, 1932, the present writer undertook to study the effect of brilliant green in leprosy, with special reference to the possibility of any renal damage that might be caused by the dye, while it is excreted through the kidneys. $\mathrm{A} \mathrm{C}_{3}$ case of leprosy with well marked cutaneous lesions, was selected, and was thoroughly examined for other co-existing disease, e.g., hook-worm, syphilis, malaria, etc., and after making sure that he was free from all other complicating affections, he was put on to brilliant green intravenously once a week. To begin with, a 1 in 5,000 solution of the dye in physiological saline, was used. Commencing with 10 c.c., the dose was gradually increased by 5 c.c. each week, until 50 c.c. was reached. Every week the urine was examined both immediately after the injection as well as on the next day of the injection. No trace of the dye could be detected in the urine and no evidence of any damage to the renal epithelium was observed.

With a view to reducing the bulk of the fluid injected and to increasing the concentration of the dye, a one in 3,000 solution was next used. After 50 c.c. was reached, without any apparent benefit, a 1 in 1,000 solution was used for some time. With the arrival of Dr. R. G. Cochrane (Medical Secretary, B.E.L.R.A.) in January, 1933, interest in this experiment was quickened, and it was thought desirable to use a stronger solution of the dye. Meanwhile Dr. R. G. Cochrane received an advance copy (in a private communication) of the "Preliminary Report on the Action of Certain Dyes in Leprosy," by Dr. G. A. Ryrie, which was subsequently published in the Transactions of the Royal Society of Tropical Medicine, Vol. 27, No. (1), June, 1933. And this advance copy the writer was privileged to go through, by the courtesy of Dr. R. G. Cochrane. This "Preliminary Report" served still further to stimulate our interest in the use of these dyes in leprosy, and we decided to make a thorough trial of brilliant green, trypan blue, and Bonney's blue. This experiment, initiated by Dr. R. G. Cochrane, has been continued by the writer up to date, and the results are reported on in this paper. 
MATERIAL FOR STUDy.

Twenty inmates of this colony, mostly $\mathrm{C}_{2}$ and $\mathrm{C}_{3}$ cases, with well-marked lesions, were selected, and were carefully examined for the presence of any other co-existing disease or diseases which might adversely influence their response to the experimental treatment. Appropriate examinations were made for the presence of syphilis, malaria, hook-worm, or any other helminthic infection (the chief predisposing factors here) and when found, the necessary treatment was administered. After careful charting of their leprous lesions and bacteriological examinations of skin and nasal smears, they were subjected to the experimental treatment. BRILLIANT GREEN.

A one per cent. solution in physiological saline was used intravenously once a week. The required quantity of the solution was prepared freshly every week, just before use. Five cases (one $\mathrm{C}_{3}-\mathrm{N}_{2}$ case, two $\mathrm{C}_{2}-\mathrm{N}_{2}$ cases and two $\mathrm{C}_{1}-\mathrm{N}_{2}$ cases) were put on to this dye, and the treatment lasted for a period of from 9 months and 1 week to 10 months and 3 weeks. Their doses ranged from 5 c.c. to 12 c.c. More than 12 c.c. could not be given, as even smaller doses than that produced prolonged reactions. Only one case stood up to 12 c.c. ; three could not take more than 10 c.c., and one could not tolerate more than 7 c.c. The usual precautions necessary for an intravenous injection of an unknown dye were taken and the injections were done under the personal supervision of the writer.

RESUlTS.

Of the five cases treated, two have improved to a certain extent, both clinically and bacteriologically ; one is worse ; and two are stationary. The case which has become worse, Girish Mahato, is the one who was originally treated with the very dilute solutions of the dye intravenously from September, 1932, to see if the dye had any adverse effect on the kidneys. So, he may be considered to have had the longest treatment with the dye (for nearly 1 year and 8 months) and yet he is worse after the treatment. Of the two cases who have improved to a certain extent, one, a boy, Hari Har Sarkar, with erythematous lesions all over, was probably in the reacting phase when he came in ; and the improvement can, at least in part, be reasonably attributed to the subsidence of the reaction; better living conditions (good food, hygienic lodgings, surroundings, medical attention, etc.) that ensued his admission into this institution, may explain the other part. This is the opinion of Dr. E. Muir also, who saw this case some time 
back. As for the other improved case, it is a debatable question whether she would not have improved without the brilliant green. Recognising the limitations incidental to the experiment, it seems permissible to conclude that brilliant green does not appear to be therapeutically more active than hydnocarpus derivatives or even equal to them.

\section{TRYPAN BLUE.}

A four per cent. solution in physiological saline was used intradermally once a week, to begin with, and was found to be too irritating. It was replaced by a one per cent. solution which was used both intradermally as well as intravenously, on the advice of Dr. E. Muir, once a week. Six cases (three $\mathrm{C}_{2}-\mathrm{N}_{2}$ cases and three $\mathrm{C}_{3}-\mathrm{N}_{2}$ cases) were selected for this experiment, and their treatment lasted for a period of from 7 to 9 months. Their doses ranged from 1 c.c. to 12 c.c. More than 12 c.c. could not be given as even smaller doses produced fairly prolonged lepra reactions. One $\mathrm{C}_{2}-\mathrm{N}_{2}$ case, Chandra Das, could not stand more than 5 c.c., as he was getting reactions in his eyes, each time he was injected with the dye. Even 3 c.c. was observed to cause a prolonged reaction in his eyes, and this probably was a case of special idiosyncracy to the dye. Needless to say, he has not improved. It may be reiterated here that only a fresh solution of the dye, prepared just before use, every week, was used, as it was found that solutions more than a day old were too irritating. One case was able to stand 12 c.c. doses without reaction, but could not tolerate anything more than that. Another case could not take more than 10 c.c. The rest (three cases) were unable to stand more than 7 c.c. a week. Here also, individual idiosyncracy seems to play a part.

Results. - Of the six cases treated; only one has shown a very slight improvement clinically. All the rest are stationary. The relative focal concentration of the dye in leprous lesions, observed by Ryrie, was also noticed in all these patients; but no appreciable effect on the lesions, or on the M. leprae, could be obtained. The trypan blue used in these cases was obtained from Messrs. Smith Stanistreet and Co., Ltd., Calcutta, and it was a Grubler's product. So there is no question of want of potency or an unreliable brand having been used, to account for the very poor results obtained. And the results of this experiment are in marked contrast with the very favourable opinions expressed by Ryrie (Ibid). It may be argued that Ryrie used a 4 per cent. solution and was therefore able to obtain a greater concentration of the dye in the lesions, whereas I have used 
a weaker solution (one per cent. only). But, as already mentioned before, I could not use a stronger solution. The 4 per cent. solution was found to be too irritant. And even the 1 per cent. solution has to be used carefully, commencing with small doses and increasing the dose very very gradually. Probably Ryrie's patients were comparatively stronger, and had a higher degree of general resistance and tolerance to the dye. Under the conditions of this experiment, the writer could not get any appreciable result with this dye, and he is led to conclude that any drug which produces frequent reactions, even in small doses, cannot be considered to be suitable for trial in cutaneous cases of leprosy of the fairly advanced types. It may also be observed here, in passing, that such startling results as are reported to have been obtained by Ryrie (Ibid), viz., bacteriologically positive cases becoming negative after a month's treatment, were not obtained by the writer, and such results may reasonably be explained by supposing that either those cases were very probably in the reacting phase when they were taken for the experiment, and with the subsidence of the reaction most of the bacilli disappeared from the skin lesions, or that the bacilli lost their acid fast characteristics, by the influence of the dye.

Bonney's Blue.

This consists of a mixture of brilliant green and crystal violet in equal parts, dissolved in alcohol and water :-

$\begin{array}{lll}\text { Brilliant Green } & \ldots & 0.5 \text { grms. } \\ \text { Crystal Violet } & \ldots & 0.5 \text { grms. } \\ \text { Absolute Alcohol } & \ldots & 25 \text { c.c.m. } \\ \text { Distilled Water to } & \ldots & 2500 \text { c.c.m. }\end{array}$

The crystal violet is first dissolved in alcohol, and is then added to the aqueous solution of brilliant green ; and the total quantity is made up to 2,500 c.c.

A large quantity of this solution was very kindly made up and sent to us for trial, by Dr. C. S. Ryles himself, who was the first to use it in his out-patient clinics in Dhanbad. Nine suitable cases (six $\mathrm{C}_{3}-\mathrm{N}_{2}$ cases and three $\mathrm{C}_{2}-\mathrm{N}_{2}$ cases) were selected, and they were treated intramuscularly and intradermally with this preparation for a period of from $9 \frac{1}{2}$ to $10 \frac{1}{2}$ months. They were given as usual weekly injections of this preparation and their doses ranged from 1 to 12 c.c. One case only (a Santali, Mara Majhi) was able to stand up to 12 c.c. intradermally. More than 4 c.c. could not be given intradermally at one time, as it was found to be too painful. In some cases a good deal of local reaction 
ensued after the intradermal injection, but the resulting improvement was in no way commensurate with the reaction induced. When administered intramuscularly, too, the same irritation was noticed, resulting in localised hardness of the muscles at the site of injection, in spite of vigorous massage after the injection. One case in this batch of nine, was kept on to intramuscular injections only, as he could not stand the intradermal injections owing to his proneness to develop keloids at the site of the injection, even after taking $\frac{1}{2}$ c.c. or 1 c.c. intradermally.

Results. - All are stationary and not a single case has shown the slightest sign of improvement either clinically or bacteriologically. Intradermal injections of the iodised or creosoted esters of hydnocarpus, or of the heated oil, do show at least some appreciable clinical improvement and some slight but definite influence on the bacteriological findings in $C_{3}$ cases, in a period of 9 to 10 months, whereas Bonney's blue, used in the same way, does not appear to exert any appreciable influence either on the M. lepræ or on the lesions of leprosy, within the same period. Further particulars concerning these cases are given in the table appended.

\section{Discussion.}

The results obtained by this experimental trial do not encourage one in the belief that these dyes have a future in the treatment of leprosy. The hopes induced by Ryrie's paper (Ibid) have not been fulfilled by this study. The writer is well aware of the criticisms that may be raised against this study-and to meet them, a short discussion here is deemed necessary, It may be laid down as a dictum that in carrying out any experiment with a view to ascertaining the therapeutic efficacy of a drug in such a chronic disease as leprosy, the fallacies connected with such an attempt, mentioned by Muir (1926), should be carefully borne in mind, and measures adopted to rule out such fallacies. Accordingly, in carrying out this study, the predisposing factors have been carefully studied and treated whenever possible, and cases found to be obviously in the reacting phase have not been selected for the experiment. To obviate the influence of the personal factor in carrying out this study only highly bacteriologically positive cases have been selected, with a view to having an unmistakable criterion of improvement, as it was felt that opinions based on purely clinical findings, such as the increase or decrease in extent of anæsthesia or slight changes in the colour of a hypopigmented patch, might be erroneous, as these changes 
have been known to occur even without the use of any particular drug.

Comparative insufficiency of dosage might be advanced as a reasonable criticism against this experiment-and in reply to this the writer has to point out that the maximum limit of tolerance in each case was studied and the maximum tolerated dose was given. Comparatively speaking, Ryrie's patients have tolerated considerably higher doses, and it is also to be noted that most of his patients were Chinese, i.e., lighter-skinned. Is it possible that lighter skinned races can tolerate higher doses of the dyes? This raises an interesting point for further study. In the case of mercurochrome, a fluorescein compound of mercury, the writer and his colleague, (Rao and Roy), have shown that Indians could not tolerate the doses recommended for Europeans. Is it not reasonable to suppose from the analogy with mercurochrome, that dark-skinned races probably cannot stand the aniline dyes in such high concentrations as the Chinese and other lighter-skinned races?

The period of treatment has been sufficiently long to enable one to judge whether the drug used has any appreciable influence on the course of the disease or not; and the longer period of treatment may help to make up for the comparative infrequency of the injections (Ryrie has given the injections twice or even thrice a week in a few cases). The bacteriological examinations and charting of cases have been carried out by the same observer, and no difference in the standards of accuracy of observation by two different persons can be held to account for the poor results obtained.

\section{Summary AND Conclusions.}

(1) The results of an experimental study with brilliant green, trypan blue and Bonney's blue, in 20 cases of leprosy (inmates of the Purulia Leprosy Colony) are reported on.

(2) These dyes used in the doses mentioned in the text of this paper, were found to have no appreciable effect either on the course of the disease or on the causative organisms, the M. lepræ.

(1) Ryrie, G. A. (1933). " Preliminary Report on the Action of Certain Dyes in Leprosy." Trans., Roy. Soc. Trop. Med., Vol. 27, No. 1. June (1933).

(2) Muir, E. (1926). "Some Fallacies connected with the Testing of Drugs for their Efficacy in the Treatment of Leprosy." Ind. Jour. Medl. Res., 1926, July. Vol. 14, No. (1), pp. 125-128.

(3) Rao \& Roy (1932). "Mercurochrome-220 Soluble in Leprosy Work." Ind. Medl. Gaz., March, 1932. 


\begin{tabular}{|c|c|c|c|c|c|c|}
\hline $\begin{array}{l}\text { Ser- } \\
\text { ial } \\
\text { No. }\end{array}$ & Name. & $\begin{array}{l}\text { Type } \\
\text { on } \\
\text { admis- } \\
\text { sion. }\end{array}$ & \multicolumn{2}{|c|}{$\begin{array}{l}\text { Preparation } \\
\text { used and } \\
\text { Method } \\
\text { of Injection. }\end{array}$} & $\begin{array}{c}\begin{array}{c}\text { Period } \\
\text { of } \\
\text { Treatment }\end{array} \\
\text { The }\end{array}$ & $\begin{array}{c}\text { Dose } \\
\text { Range }\end{array}$ \\
\hline 1 & Harish Kallyan & $\mathrm{C}_{1}-\mathrm{N}_{2}$ & \multicolumn{2}{|c|}{$\begin{array}{l}\text { I3rilliant Green } \\
1 \% \text { sol. I.V. }\end{array}$} & $\begin{array}{l}\text { mths. } \\
8-10+1\end{array}$ & 5 c.c. to 10 c.c. \\
\hline 2 & Hari Har Sircar & $\mathrm{C}_{2}-\mathrm{N}_{2}$ & do. & I.V. & $8-10 \frac{1}{4}$ & 5 c.c. to 7 c.e. \\
\hline 3 & Girish Mahato & $\mathrm{C}_{1}-\mathrm{N}_{2}$ & do. & I.V. & $8 \frac{1}{4}-10 \frac{3}{4}$ & 5 c.c. to 10 c.c. \\
\hline 4 & Mothi Mahindi & $\mathrm{C}_{3}-\mathrm{N}_{2}$ & do. & I.V. & $5 \frac{1}{2}-9 \frac{1}{4}$ & 5 c.c. to 12 c.c. \\
\hline 5 & Jhalu Mahatàn & $\mathrm{C}_{2}-\mathrm{N}_{2}$ & do. & I.V. & $6 \frac{1}{1}-10 \frac{1}{2}$ & 5 c.c. to 10 c.c. \\
\hline 6 & Kina Majhi & $\mathrm{C}_{2}-\mathrm{N}_{8}$ & $\begin{array}{l}\text { Trypar } \\
\text { Sol. I.I }\end{array}$ & $\begin{array}{l}\text { Blue, } 1 \% \\
\text { I. \& I.V. }\end{array}$ & $6 \frac{1}{2}-7+\frac{8}{4}$ & 1 c.c. to 12 c.c. \\
\hline 7 & Madhu Sudon & $\mathrm{C}_{3}-\mathrm{N}_{1}$ & & & $5-7$ & 1 c.c. to 7 c.e. \\
\hline 8 & Dinu Mahato & $\mathrm{C}_{3}-\mathrm{N}_{2}$ & & & $5 \frac{1}{1}-7 \frac{1}{8}$ & 1 c.c. to 7 c.c. \\
\hline 9 & Chandra Dass & $\mathrm{C}_{2}-\mathrm{N}_{2}$ & & & $5 \frac{3}{3}-7 \frac{1}{8}$ & 1 c.c. to 5 c.c. \\
\hline 10 & Kristo Mahato & $\mathrm{C}_{2}-\mathrm{N}_{2}$ & & & $6 \frac{1}{2}-6$ & 1 c.c. to 10 c.c. \\
\hline 11 & Durga Charon & $\mathrm{C}_{2}-\mathrm{N}_{2}$ & & & $6-9$ & 1 c.c. to 7 c.c. \\
\hline 12 & Mara Majhi & $\mathrm{C}_{3}-\mathrm{N}_{2}$ & $\begin{array}{c}\text { Bonney } \\
\text { I.I }\end{array}$ & $\begin{array}{l}\text { s Blue, } \\
\text {.I. }\end{array}$ & $8 \frac{1}{8}-10 t$ & 1 c.c. to 12 c.c. \\
\hline 13 & Arjun Mahato & $\mathrm{C}_{2}-\mathrm{N}_{2}$ & do. & I.D.I. & $7-10 \frac{1}{6}$ & 1 c.c. to 4 c.e. \\
\hline 14 & Sombhu Mahato & $\mathrm{C}_{3}-\mathrm{N}_{2}$ & do. & I.M. & $8 \frac{1}{6}-10 \frac{1}{2}$ & 2 c.c. to 5 c.e. \\
\hline 15 & Bharot Bartholmoy & $\mathrm{C}_{2}-\mathrm{N}_{2}$ & do. & I.D.I. & $7 \frac{1}{2}-10 \frac{1}{2}$ & 1 c.c. to 4 c.c. \\
\hline 16 & Khetu Sorder & $\mathrm{C}_{2}-\mathrm{N}_{1}$ & do. & I.D.I. & $6 \frac{1}{2}-10 \frac{1}{2}$ & 1 c.c. to 4 c.e. \\
\hline 17 & Rongi Rahel & $\mathrm{C}_{3}-\mathrm{N}_{2}$ & do. & I.D.I. & $5 \frac{1}{d}-9 \frac{1}{2}$ & 1 c.c. to $2 \frac{1}{8}$ c.e. \\
\hline 18 & Tushia Mahatan & $\mathrm{C}_{3}-\mathrm{N}_{2}$ & do. & I.D.I. & $7 \frac{1}{6}-10 \frac{1}{2}$ & 1 c.c. to $3 \frac{1}{2}$ c.e. \\
\hline 19 & Dhumi Mahatan & $\mathrm{C}_{3}-\mathrm{N}_{2}$ & do. & I.D.I. & $7-10 \frac{1}{6}$ & 1 c.c. to 4 c.c. \\
\hline 20 & Niroda Nirmota & $\mathrm{C}_{3}-\mathrm{N}_{2}$ & do. & I.D.I. & $6-10 t$ & 1 c.c. to 4 c.c. \\
\hline
\end{tabular}




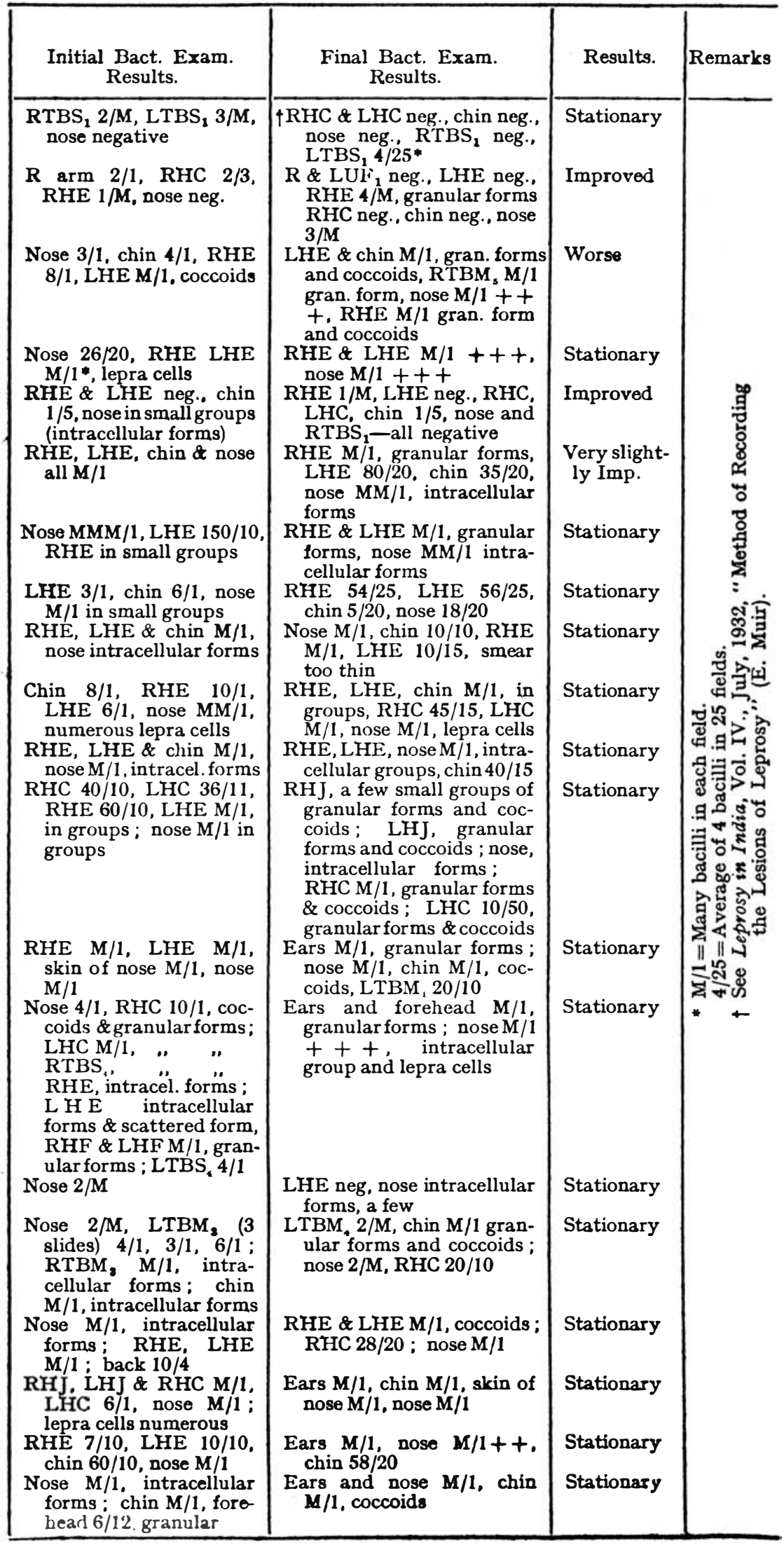

